\title{
Analysis of the wave-flow interaction with submerged breakwaters
}

\author{
A. C. Neves, F. Veloso Gomes \& F. Taveira Pinto \\ Institute of Hydraulics and Water Resources, \\ Faculty of Engineering of the University of Porto, Porto, Portugal
}

\begin{abstract}
The use of submerged breakwaters against coastal erosion problems has some advantages when compared, for example, with the use of similar emerged coastal protection structures and for that reason their use in coastal protection is becoming popular all over the world. Their effect in the wave field and especially in the wave-induced velocities has been analysed by several authors though there is still a lack of knowledge on the wave-flow interaction.

The aim of this study was to analyse the behaviour of submerged breakwaters and especially the wave induced velocity field, which can have great impact in the stability of the structures and in the sediment circulation.

Two-dimensional scaled physical tests were carried out in the Hydraulics Laboratory wave tank of the University of Porto, in order to understand with more accuracy the influence of the permeability and of the submergence of the breakwaters in the wave-structure interaction. For that reason, tests were performed with the same wave conditions (regular waves), with two different models with the same geometry, one with permeable and one with impermeable rough slopes, and with two water depths (leading to two different freeboards of the structure).

Keywords: submerged breakwater, wave-flow interaction.
\end{abstract}

\section{Introduction}

Several investigations have been performed in relation to submerged breakwaters. Although much is already known in what concerns to the stability of these structures, it is believed that there is a lack of information about the hydrodynamics in their vicinity, namely in the velocity field. 
Losada et al. [1], in DELOS research report, have referred that the knowledge of the velocity field in the immediacy of submerged breakwaters is essential in what respects to the stability of the blocks. The authors have developed a numerical model, calibrated by several experimental results, to the prediction of the behaviour of submerged breakwaters and their influence in the wave propagation and in the water particle velocities. A high degree of agreement between th numerical and experimental data relatively to the free surface displacement in the vicinity of the structure and the velocities in the seaward slope was found.

Tirindelli and Lamberti [3], also analysed velocities in the proximity of the stones of the armour later of submerged breakwaters. Through Morrison-type equations, the authors have calculated the wave forces in armour stones. They also pointed out the importance of knowing the velocity and acceleration of the water particles in the proximity of the blocks, as the wave-induced force applied to an armour unit depends on them.

Saitoh and Ishida [2] analysed the wave-flow interaction with submerged breakwaters, namely velocity field in their proximity. Experiments with an impermeable model using PIV measurements and Laser Dopper Anemometry have been performed with several wave conditions. It was found that the maximum velocity offshore occurred in the upper part of the slope. Mass transport velocity and acceleration, among other parameters were also calculated, once they were considered to strongly affect the stability of the blocks and erosion at the toe of these structures.

Taveira-Pinto [4] also analysed the velocity field near submerged breakwaters, through experimental modelling. The author has found high values of the turbulence intensity near the bottom and near the surface, in sections where an inversion of the flow velocity occurred and where the flow was passing over the obstacle. This last observation could be explained by the flow constriction occurring due to the water depth reduction in this section.

It is considered that much of the existent literature has not paid significant attention to the influence of the roughness and of the permeability of the submerged breakwaters in the velocity near and far field and, thus, the aim of this study was to analyse the behaviour of submerged breakwaters and, especially the wave induced velocities near them and the parameters influencing them

\section{Experimental set-up}

The experiments were conducted in the Hydraulics Laboratory of the Faculty of Engineering of the University of Porto. The wave tank is $12 \mathrm{~m}$ wide, $28 \mathrm{~m}$ long and has a maximum water depth of $0.6 \mathrm{~m}$. A thin dividing wall was used to isolate the measuring section from the rest of the tank, avoiding threedimensional effects and wave diffraction during the tests. A gently inclined absorbing beach was also constructed, diminishing wave reflection by causing sufficient dissipation of wave energy. A piston-type wave maker was used. 
Two models of submerged breakwaters were used: a rough impermeable model and a rough permeable one, in order to analyse the effect of the permeability in the wave-velocity field. The models had similar cross-section, with a $0.30 \mathrm{~m}$ crest width, a $0.40 \mathrm{~m}$ crest height and $1 / 1$ slopes. Figure 1 shows the rough impermeable model, where stones $(\mathrm{Dn} 50=4.4 \mathrm{~cm})$ were glued to a perspex base, simulating an armour layer. The permeable model had an armour layer of 2 Dn50 width and a nucleus.

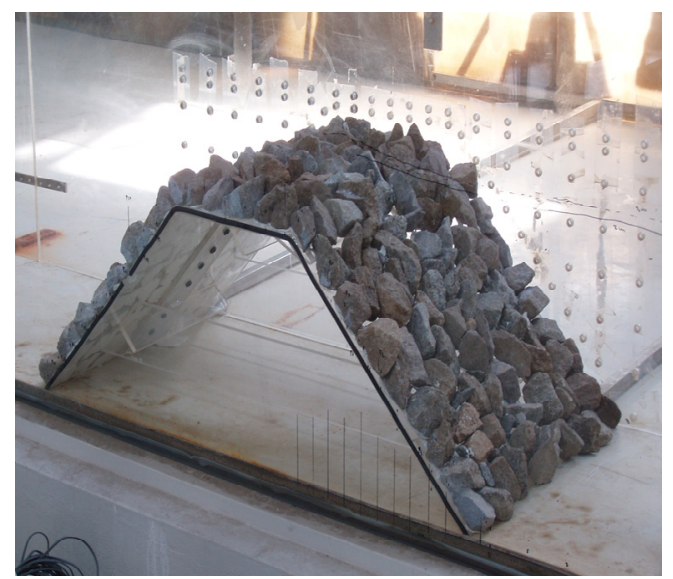

Figure 1: Rough impermeable model.

The velocity measurements were done in different vertical profiles, at different distances from the bottom and, successively nearer to the models, using Laser Doppler Anemometry technique. The optical system was formed by an Argon-Ion Laser, modular LDA optics based on a one-component fibre optic system and a $60 \mathrm{~mm}$ probe, working in a backscatter configuration.

A capacitance wave probe was placed outside the testing section in order to verify the incident wave and in the vertical alignment where the velocity component was being measured.

A Burst Spectrum Analyser allowed the simultaneous record of the analogical signals relative to the instantaneous water surface elevations and the Doppler signal relative to the velocity, in a way that each validated velocity corresponded to a water surface elevation value.

The testes were performed with regular waves, with the same characteristics: $\mathrm{H}=0.065 \mathrm{~m}$ and $\mathrm{T}=1.5 \mathrm{~s}$. Two water depths were tested, allowing the analysis of the effect of the submergence of the model in the velocity-field, $0.4 \mathrm{~m}$ and 0.45 $\mathrm{m}$, which is equivalent to a 0 and $\mathrm{a}+5 \mathrm{~cm}$ freeboard.

\section{Results and discussion}

As referred before the velocity measurements were done in different vertical profiles, at different distances from the bottom. The location of the measured profiles is indicated in Figure 2. 


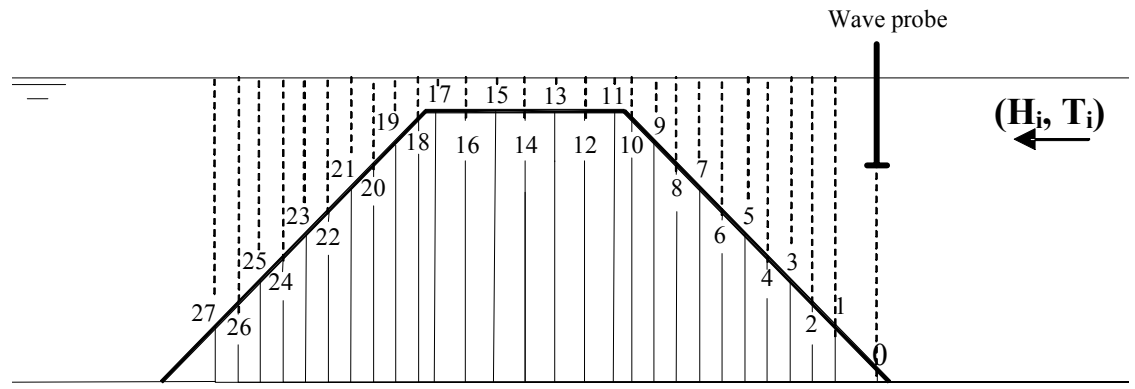

Figure 2: $\quad$ Location of the measured profiles.
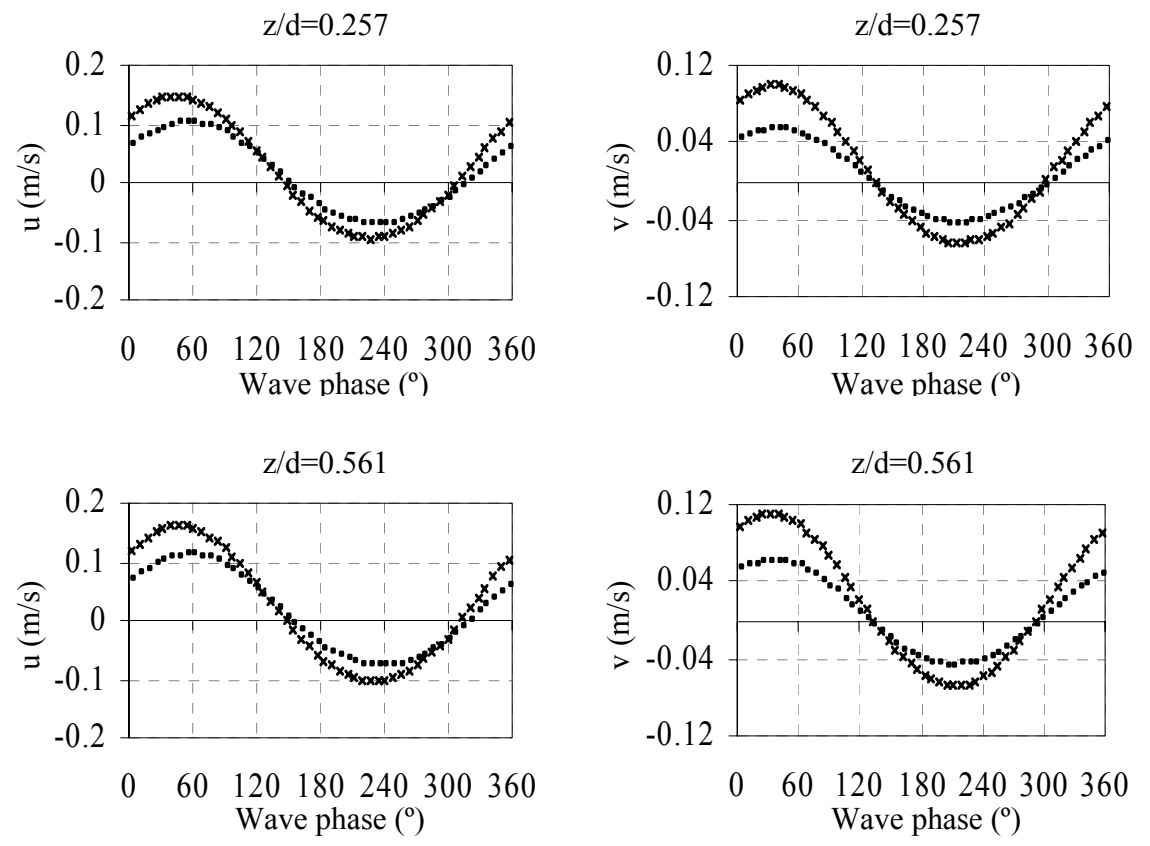

$\times$ rough impermeable model $\cdot$ rough permeable model

Figure 3: Mean values of the horizontal (a) and vertical (b) component of the velocity $(\mathrm{H}=0.065 \mathrm{~m}, \mathrm{~T}=1.5 \mathrm{~s}, \mathrm{~d}=0.45 \mathrm{~m}, \mathrm{z} / \mathrm{d}=0.181$ and $\mathrm{z} / \mathrm{d}=0.257$, profile 1).

Each one of the measured points generated a file, with the instantaneous water surface elevation and the respective velocity component values. A specific program was then used for the wave analysis and the calculation of the mean values of the variables for 50 different phases of the wave period. Figures 3 and 4 show some of the velocity measurement results. The results respect to the 
rough impermeable and the rough permeable model and were obtained in profile 1 and profile 27, for two of the measurement levels and for one of the water depths.
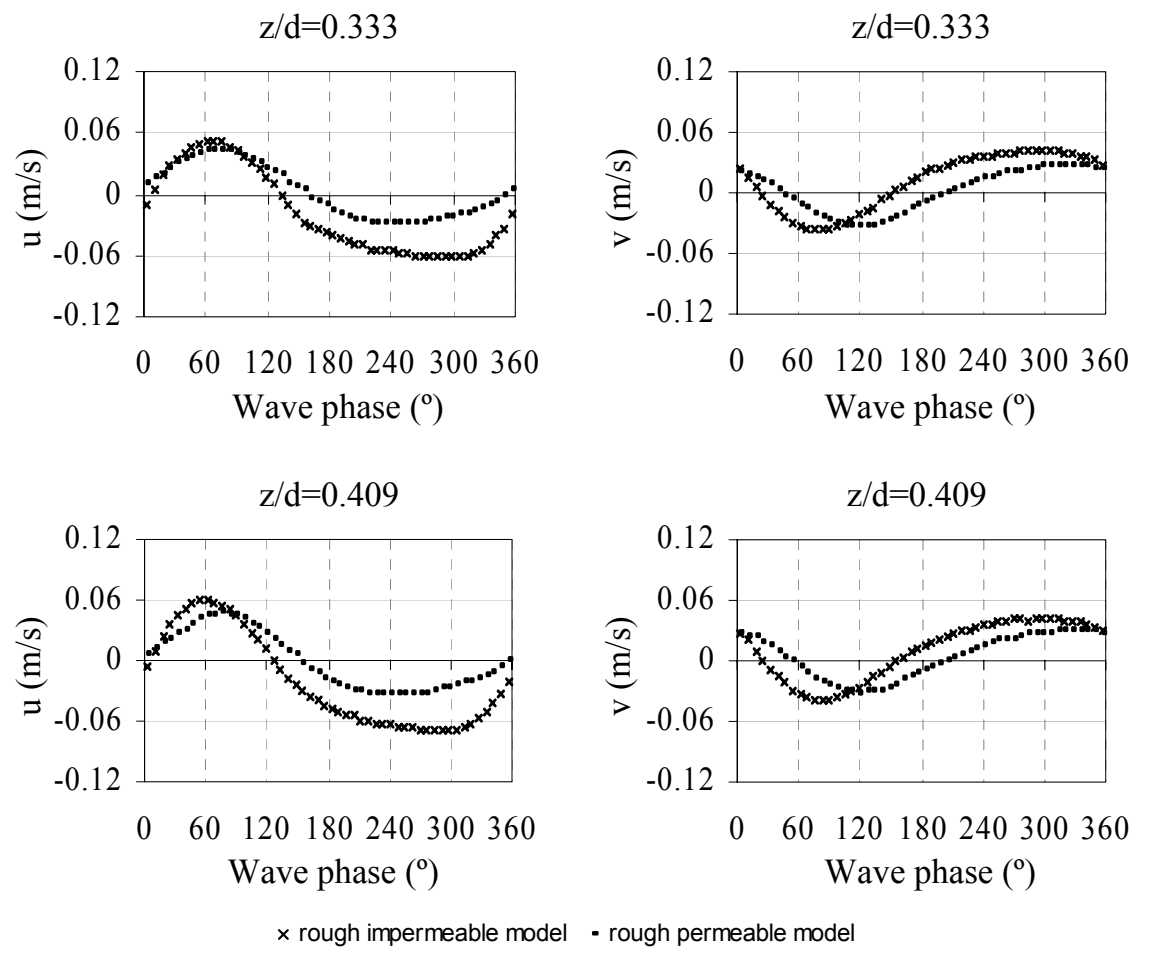

Figure 4: Mean values of the horizontal (a) and vertical (b) component of the velocity $(\mathrm{H}=0.065 \mathrm{~m}, \mathrm{~T}=1.5 \mathrm{~s}, \mathrm{~d}=0.45 \mathrm{~m}, \mathrm{z} / \mathrm{d}=0.181$ and $\mathrm{z} / \mathrm{d}=0.257$, profile 27)

The results proved that the horizontal component of the velocity is almost always greater than the vertical one. This fact is more obvious seaward of the model than in the leeward of the model, where the vertical velocity has more or less the same magnitude than the horizontal one.

It can also be seen that the permeability induces in a greater attenuation of the velocities. Both velocity components were clearly attenuated by the obstacle, as it can be seen in the comparison between figures 3 and 4 .

A great area in the vicinity of the submerged breakwater models was covered and in total, 212 points were measured with the rough impermeable model and 169 points with the rough permeable one. Phase-averaged values of the velocities were calculated and analysed as a function of the relative distance to the bottom, allowing a global analysis of the velocity field. 


\subsection{Permeability effect}

Figure 5 illustrates some of the results, where the values obtained with the rough impermeable model and the permeable one were placed in the same graphic in order to easily compare the permeability effect in the wave-induced flow velocity field.

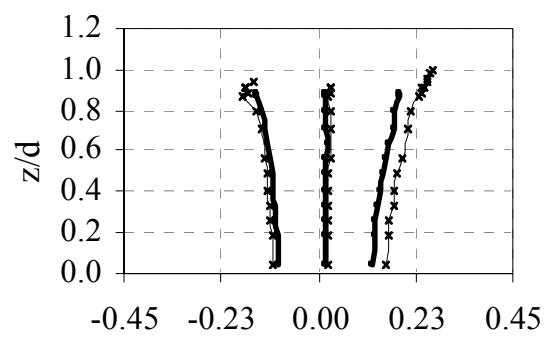

PC phase-averaged $\mathrm{u}(\mathrm{m} / \mathrm{s})$

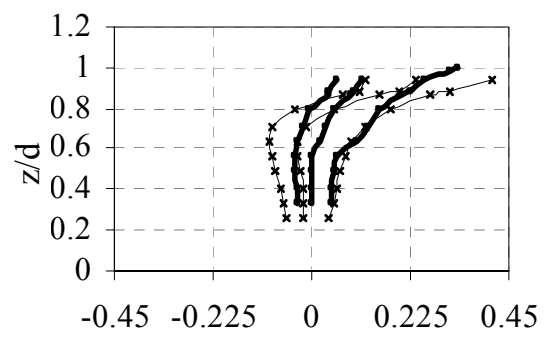

PC phase-averaged $\mathrm{v}(\mathrm{m} / \mathrm{s})$

$\longrightarrow$ impermeable model

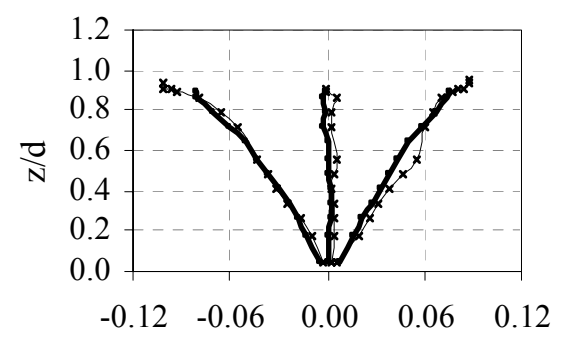

P27 phase-averaged $\mathrm{u}(\mathrm{m} / \mathrm{s})$

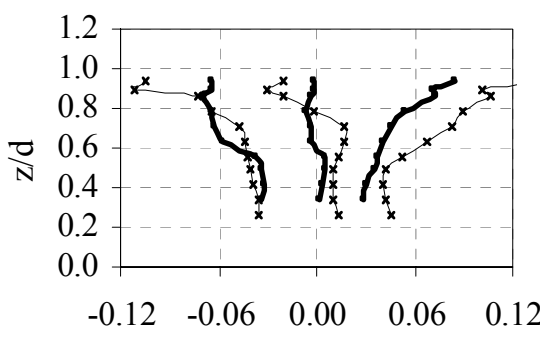

P27 phase-averaged $\mathrm{v}(\mathrm{m} / \mathrm{s})$ - permeable model

Figure 5: Variation along relative distance to the bottom of the mean, maximum and minimum values of both velocities components for permeable and impermeable models, profiles $\mathrm{C}$ and 27.

The graphics clearly illustrate that permeability has an important role in the attenuation of the flow velocities. In the permeable model, the water percolates inside the structure, which allows the dissipation of velocities through it, instead of concentrating them only in the surface, conducting the mean horizontal velocities in the permeable model to be most of the time lower than the ones obtained in the impermeable one, in profiles located seaward of the model or in the seaward slope. This can be explained by the effect of the structure's permeability in the decreasing of the reflection properties of the breakwater model, which attenuates the seaward wave-induced velocities. On the other hand, it was found that the percolation of the flow through the structure caused an increment of the horizontal component of the velocity in the bottom region till the crest of the structure, as it can be seen in the graphic that respects to phaseaveraged horizontal velocity results calculated for profile 27 . 
It was found that the most critical areas, in terms of velocities were located along the crown and in the upper part of the seaward slope. The upper part of the leeward slopes also revealed large mean horizontal velocities.

The results proved that the permeable breakwater had greater impact in terms of wave energy dissipation than the other model, allowing a significant reduction of the horizontal velocities in the upper sections.

\subsection{Freeboard of the structure effect}

A similar analysis was performed for the results obtained with the two water depths. Figure 6 represents some of the results. The used water depths, 0.40 and $0.45 \mathrm{~m}$ conducted to submergences of $0 \mathrm{~cm}$ (mean water level coincident with the crest of the model) and $5 \mathrm{~cm}$, respectively. In total, 169 points were measured with the $0.45 \mathrm{~m}$ water depth and 111 points with the $0.40 \mathrm{~m}$ water depth.

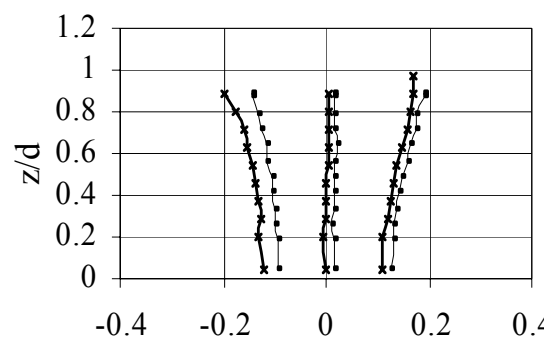

PC phase-averaged $\mathrm{u}(\mathrm{m} / \mathrm{s})$

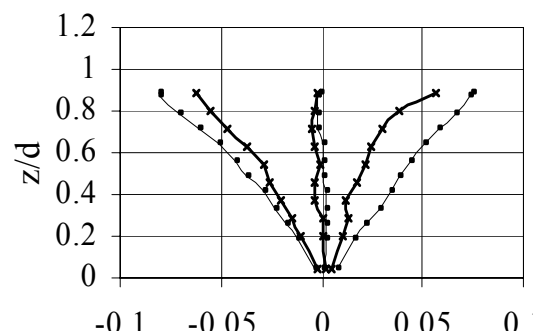

PC phase-averaged $\mathrm{v}(\mathrm{m} / \mathrm{s})$ $\rightarrow \mathrm{F}=-5 \mathrm{~cm}$
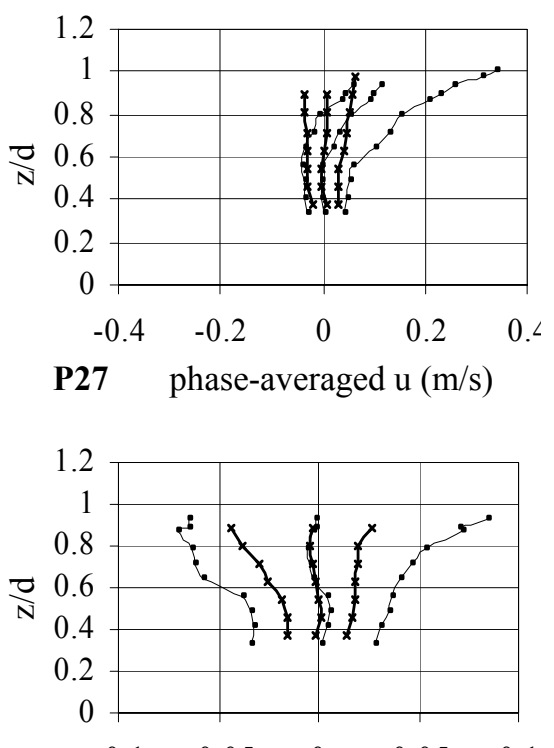

P27 phase-averaged $\mathrm{v}(\mathrm{m} / \mathrm{s})$

$\rightarrow \mathrm{F}=0 \mathrm{~cm}$

Figure 6: Comparison of phase-average velocities near submerged breakwaters, for different freeboards, profiles C and 27.

The results have proved that the submergence of the structure affects the wave-induced flow characteristics. The results obtained with the zero freeboard were almost always smaller than the ones found in the $+5 \mathrm{~cm}$ submergence case. These differences were especially significant in the profiles located leeward of the model, in the sections above the structure, due to the (in)existence of 
overtopping. When $\mathrm{d}=0.45 \mathrm{~m}$, for example, it can be observed the enlargement of the mean velocities in the leeward of the model, directed onshore, while for $\mathrm{d}=0.40 \mathrm{~m}$, the respective velocities are much closer to zero.

\section{Conclusions and final remarks}

Experimental tests were conducted with two models of submerged breakwaters with different permeability characteristics for the same wave conditions. The results have confirmed that permeability of these structures can strongly affect the wave-induced flow characteristics, seawards and leewards of the structure. Most of the time, the mean horizontal velocities registered in the permeable model were lower than the ones obtained in the impermeable model, due to the effect of the structure's permeability that decreases the reflection properties of the breakwater model and consequentially attenuates the seaward flow velocities.

Different structure's freeboards were also tested and the results of the measurements proved that the level of the crest of structure in relation to the mean water level has great influence in the wave-induced velocities, as it influences the passage of water over the structure.

It is intended to extend this analysis to other characteristics of the models, such as the roughness of the surface, in the wave-induced flow. Other wave conditions are also being tested, in other to investigate their influence in the flow field. Tests with irregular waves are also intended to perform in order to prove the validity of the conclusions.

\section{References}

[1] Losada, I., Garcia, N., Lara, J., 2005. Report on turbulent flow velocities in the surface region of low-crested structures. DELOS (Environmental Design of Low Crested Coastal Defence Structures) Project, Deliverable 23 and 44.

[2] Saitoh, T., Ishida, H., 2001. Kinematics and Transformation of New Type Wave Front Breaker Over Submerged Breakwater. Proceedings of the 4th International Symposium Waves 2001, San Francisco, USA, ASCE, volume II, pp. 1032-1041, ISBN 0-7844-0604-9.

[3] Tirindelli, M., Lamberti, A., 2004. Wave-induced forces on Structural and Biotic Elements of Low Crested Structures, Proceedings of the $29^{\text {th }}$ International Conference Coastal Engineering 2004, Lisbon, Portugal, pp. 4228-4239.

[4] Taveira-Pinto, F. 2001. Velocities Fields in the Vicinity of Submerged Breakwaters, PhD Thesis, Faculty of Engineering of University of Porto (in Portuguese), Porto, Portugal 